\title{
Carbon Fiber Reinforced Polymer and Epoxy Adhesive Tensile Test Failure Analysis Using Scanning Electron Microscopy
}

\author{
Dany Arnoldo Hernandez ${ }^{a}$, Carlos Alberto Soufen ${ }^{b}$,Marcelo Ornaghi Orlandi ${ }^{a *}$ \\ ${ }^{a}$ Instituto de Quimica, Universidade Estadual Paulista, Araraquara, SP, Brazil \\ ${ }^{b}$ Departamento de Engenharia Mecânica, Universidade Estadual Paulista, Bauru, SP, Brazil
}

Received: February 25, 2017; Revised: May 29, 2017; Accepted: June 03, 2017

\begin{abstract}
Morphological characteristics analysis before and after tensile tests were studied using scanning electron microscopy (SEM) technique to follow the failure evolution on carbon fiber reinforced polymer (CFRP) and epoxy resins. Micrograph analysis of CFRP plate before tensile test shows some intrinsic manufacturing defects, which can influence the mechanical properties of the material. Micrograph analysis after tensile test shows that cracks propagation start in manufacturing defects, which lead the carbon fiber to be pulled out instead of breaking. Thus, cracks propagate through interfacial zones affecting the sharing force between matrix and carbon fiber. For the epoxies materials, the microscopy analysis showed that although epoxies adhesive have different phase distribution before tensile test, failure surfaces are described by fine granular particles covalent bonded with matrix, and the material fails in a brittle manner when the strength outstripped these bonds. Failure process for each material correlating the mechanical properties with the morphological characteristics of materials was discussed.
\end{abstract}

Keywords: Carbon fiber reinforced polymer, electron microscopy, tensile test

\section{Introduction}

Fiber reinforced polymer (FRP) composite systems and epoxy adhesive are important materials in civil engineering. However, although the morphological characteristics of FRP have close correlation with its mechanical properties, they have not been deeply studied using scanning electron microscopy (SEM) technique. Nowadays, in order to understand failure sequences of FRP composites and epoxy adhesives it has been correlated to the mechanical behavior of composites materials when they are used in retrofitting any concrete or steel element ${ }^{1-7}$. In addition, majority of researches that have focused on FRP composites and epoxy adhesive mechanical behavior did not explore the morphology of materials. Hassein ${ }^{8}$ studied how temperature affects the strength and the fatigue life of steel beams strengthened with externally bonded carbon FRP (CFRP) plates. In CFRP tensile test it was found that samples failed without any plastic deformation. Besides, tensile tests for sikadur 30 dogbone specimens were carried out and showed a nonlinear stress-strain behavior when the temperature is close and above the material glass transition temperature $(\mathrm{Tg})$.

Others researchers explored the resin bond behavior and its mechanical resistance. It deserves attention because typically the adhesive of the FRP composite system fails first in the mechanical tests. Michels et al. ${ }^{9}$ studied the influence of the curing condition (room temperature or accelerated curing) in glass transition temperature (Tg) of Sikadur 30, using Dynamic Mechanical Analysis (DMA) in the

*e-mail: orlandi@iq.unesp.br temperature range from $-20^{\circ} \mathrm{C}$ to $150^{\circ} \mathrm{C}$. It was observed that glass transition temperature $(\mathrm{Tg})$ can present values in the range from $40{ }^{\circ} \mathrm{C}$ to $50{ }^{\circ} \mathrm{C}$ depending on the curing condition. McNutt ${ }^{10}$ applied spring theory using CFRP in shear and tensile tests. Results showed that taking no notice of progressive failure of epoxy resin and assuming the epoxy resin behaves in a linear brittle manner is conservative. It was also observed that the weakest component of the composite is the epoxy resin used as adhesive.

M.D Gilchrist \& N. Svensson ${ }^{11}$ used SEM technique to study fractographic features associated with delamination in multidirectional laminates of T300/914 carbon/epoxy composite. Results showed that a very large number of broken fibers is related to the failure mode I and a large amount of resin debris due to fatigue loading is obtained. Bradly ${ }^{12}$ studied the effect of the moisture absorption on the interfacial strength of polymeric matrix composites using SEM technique to determine their potential suitability for structural applications in seawater. It was reported that the moisture-induced degradation is associated with a decrease in the interfacial strength rather than the degradation of matrix mechanical properties. Jumahat ${ }^{13}$ used a SEM and optical microscopy to propose a possible sequence of failure initiation and propagation of carbon fiber / toughened epoxy composites subjected to compressive loading. The micrographs revealed that the misaligned fibers failed in two points upon reaching maximum micro-bending deformation and two planes of fracture were created to form a kink band.

Horst ${ }^{14}$ studied the fatigue fracture mechanisms and fractography of short-glassfibre-reinforced polymide 6 . He 
observed that only a small fraction of the fibers break under fatigue; mostly of fibers are pulled out during the test. The mechanism consists as follow: damage begins with void formation, mainly at fiber ends followed by the coalescence of voids to small cracks. Arif ${ }^{15}$ studied the multiscale fatigue damage characterization in short glass fiber reinforced polymide-66 using X-ray micro-computed tomography $(\mu \mathrm{CT})$ technique on interrupted fatigue test at several percentages of total fatigue life. By the analysis of voids characteristics, he observed that the damage continuously increases during fatigue loading, and the damage is developed along the fiber interface in the form of fiber/matrix interfacial debonding.

Most of the existing researches about adhesive bonding technology and composites materials are for aeronautical and space science and other industries ${ }^{16-19}$, and lack researches has been regarded to use those polymers and composites material in civil engineering ${ }^{20-24}$. Nowadays does not exist any mandatory structural design code around the world. There are guidelines or handbooks as the Japanese (JSCE1197), the American (ACI 440-2000) as well as the European (FIP-CEB-2001) and so others but none of them have the same level of mandatory as ACI-318 for structural concrete design or AISC 360 for structural steel design, in USA, or the EURO codes, in Europa. The reason why composite material and adhesive bonding materials do not have a mandatory design code in civil engineering is due to the changes that they present over time, which are related to changes in the primary constituent. Then, it is important to focus attention in the primary constituent behavior.

Cohesive fracture is the desired failure mode when an adhesive bonding is used to fasten together two surfaces and a good adhesion between matrix and the fibers that are used as loading carrying component is necessary in composite materials. Therefore, to study in a deeply way adhesive and composite materials failure surfaces is an important contribution to this field. Nowadays, the majority of research in adhesive bonding and composites materials have been focused on determining mechanical properties, such as glass transition temperatures, lap shear behavior, using and developing different methods. However, majority of works have not studied the cross section surface before and after failure using Scanning Electron Microscopy (SEM) technique to observe the differences on the morphological characteristics. Based on the exposed before, the main objective of this work is to study the adhesive bonding cross section failure surface and the interface of matrix and fiber in composite materials using Scanning Electron Microscopy (SEM) technique and standards related to the civil engineering field.

\section{Materials and Methods}

In this work carbon fiber composite material Sikacarbodur S512 and polymer epoxies adhesives Sikadur 30 and Sikadur 330 were used. The CFRP are supplied in the forms of pultruded plates and as preimpregnated (prepreg) or dry wrap sheets. CFRP pultruded plates are bonded to the structure using a two-part epoxy adhesive, while CFRP sheets are bonded using an epoxy resin by wet lay-up technique. The sikacarbodur S512 used in this work is a pultruded unidirectional carbon fiber plate of $1.2 \mathrm{~mm}$ thickness and 5 $\mathrm{cm}$ width, with carbon fibers longitudinal direction oriented parallel to plate longitudinal direction.

Sikadur 30 is a solvent free epoxy adhesive. It is commonly used in bonding reinforcement of concrete and steel structures, presenting many advantages: i) it can be mixed and applied easily; ii) It can be cured at room temperature; iii) it has a high mechanical strength and high creep resistance; iv) it hardens without shrinkage and v) it has excellent adhesion in damp conditions. This adhesive consists of two components: the epoxy resin (part A) and the hardener (part B) which are mixed together in a weight proportion of $3: 1$.

Sikadur 330 is a solvent free, thixotropic epoxy based impregnating resin/adhesive. It is also a primer resin for the wet application system, impregnation resin for the dry application method and structural adhesive for bonding CFRP plates to even surfaces. The main advantages of Sikadur 330 are described as follow: easy mix and application by trowel and impregnation roller, excellent application behavior to vertical and overhead surfaces, good adhesion to many substrates and superior mechanical properties. This adhesive consists of two components: the epoxy resin (part A) and the hardener (part B) which are mixed together in a weight proportion of $4: 1$. Table 1 shows the manufacturer mechanical properties of Sikacarbodur S512, Sikadur 30 and Sikadur 330.

Table 1. Manufacturer mechanical properties of Sikacarbodur S512, Sikadur 30 and Sikadur 330 materials.

\begin{tabular}{lccc}
\hline & $\begin{array}{c}\text { Sikacarbodur } \\
\text { S512 }\end{array}$ & $\begin{array}{c}\text { Sikadur } \\
30\end{array}$ & Sikadur 330 \\
\hline $\begin{array}{l}\text { Density } \\
\begin{array}{l}\text { Tensile Strength } \\
\text { (MPa) }\end{array}\end{array}$ & $1.60\left(\mathrm{~g} / \mathrm{cm}^{3}\right)$ & $1.65 \mathrm{Kg} / \mathrm{l}$ & $1.30 \mathrm{Kg} / \mathrm{l}$ \\
$\begin{array}{l}\text { E-modulus(MPa) } \\
\begin{array}{l}\text { Tensile strain to } \\
\text { break (\%) }\end{array}\end{array}$ & 165,000 & 31 & 30 \\
\hline
\end{tabular}

Composite material uniaxial tensile tests were performed on fiber direction according to ASTM 3039/D3039M-14 Standard and epoxy material tensile tests were done according to ASTM D638 standard. For the standard test on Sikacarbodur S512, it was used a standard head displacement rate of $2 \mathrm{~mm} / \mathrm{min}$ and the specimens dimensions are illustrated in Figure 1.

Sikadur 30 uniaxial tensile test was made using $5 \mathrm{~mm}$ thick sample at $1 \mathrm{~mm} / \mathrm{min}$ to ensure the samples fail close to 1 minute of testing. The nominal straining rate, regarding a gauge length of $25 \mathrm{~mm}$ is $0.04 \mathrm{~min}-1$ (6.67 sec-1). For the sikadur 330 material, the thickness of samples was also $5 \mathrm{~mm}$. Specimen dimensions for the resin tests are shown in Figure 2. 


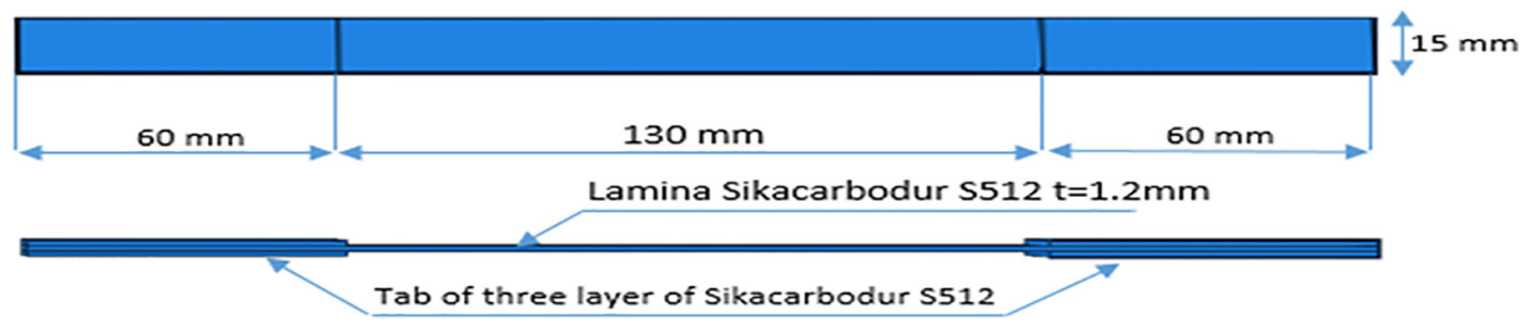

Figure 1. Carbon Fiber Reinforced Polymer standard tensile test sample.

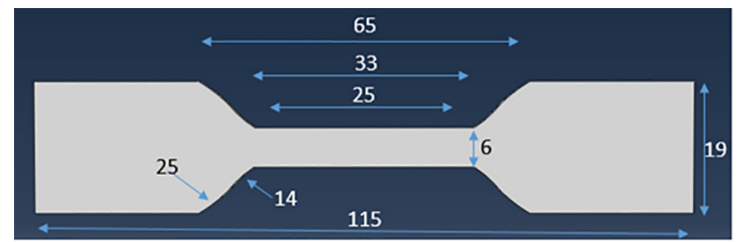

Figure 2. Illustration of Epoxy resin tensile test sample. Shown dimensions are in $\mathrm{mm}$.

For mechanical tests it was used a universal machine INSTRON/EMIC 23-200. For CFRP tensile test it was used jaws GR012 attached to a load cell CCE100kN for gripping the samples and the cell had a maximum capacity of $100 \mathrm{kN}$. For the polymers tensile tests, jaws GR003 were attached to a load cell CCE2KN for gripping the samples, and the maximum cell capacity was $2 \mathrm{kN}$, and an electronic extensometer class B-1 of $25 \mathrm{~mm}$ of gage length was used. Scanning electron microscopy (SEM) analysis were obtained using a high resolution field emission SEM (JEOL, model 7500F).

\subsection{Samples preparation}

As received CFRP Sikacarbodur S512 plate was cut using a sheet metal cutting equipment in the dimensions presented in Figure 1. Then, the surface of specimens was cleaned using acetone before sticking the tabs using Sikadur 30 adhesive. Tabs bevel angle of $90^{\circ}$ were used. In order to obtain the epoxy adhesive samples, molds were prepared in the desired dimensions using acrylic sheet and a laser cutting tool. Then, components A and B of epoxy adhesive were weighed using a scale (Shimadzu, model AX200) and a plastic cup according to the required proportion indicated in the material datasheet. After, the components A and B were poured into a clean container and mixed together using a masonry spoon by hands for about 1 minute, until the material became smooth in consistency and with uniform color. Following, the dies were filled out with the material while it was within its potlife. After, filled acrylic sheets were clamped and positioned on a press during the first 24 hours of curing. Then, they were released and positioned into an oven at $40{ }^{\circ} \mathrm{C}$ during six days to complete seven days of curing time, when cured samples were removed from the dies. Polidesmo 11 wax was used before pouring the material to avoid the samples adhering to the die. An emery cloth was used to remove all the imperfection of the borders as marks of the die or extra material at edges. Then, all the samples were kept into a clean and close container at room temperature until the tensile tests were performed. For the CFRP composite and for every epoxy adhesive at least 10 samples were tested and the reported mechanical results are an average of at least five different specimens of each material. Then, two samples of each material were chosen to be observed by electron microscopy.

For the microscopy analysis before and after tests, $3 \mathrm{mmx} 3 \mathrm{~mm}$ pieces of CFRP and $6 \mathrm{~mm} \times 5 \mathrm{~mm} \times 1 \mathrm{~mm}$ pieces of adhesive samples were cut using an electric laboratory saw. Special care was taken when cutting the samples after test to avoid any modification or contact that could distort the failed side of the samples.

\section{Results and Discussion}

\subsection{Standard tensile tests}

Tensile test results are shown in Figure 3 and the mechanical properties extracted from plots are presented in Table 2. For sikacarbodur S512 (Figure 3a) the calculated tensile strength was $3,051 \mathrm{MPa}$, the Young modulus was $166,738 \mathrm{MPa}$ and the tensile strain to break was $1.8 \%$. These values are close to values reported on material datasheet, which are 3,100 $\mathrm{MPa}, 165,000 \mathrm{MPa}$ and $1.7 \%$, respectively. For sikadur 30 (Figure 3b), the calculated tensile strength was $30 \mathrm{MPa}$, the Young modulus was $12,049 \mathrm{MPa}$ and the tensile strain to break was $0.4 \%$, which are similar to results reported by Hassein $^{8}$ and close to the datasheet values, which are $31 \mathrm{MPa}$, $11,200 \mathrm{MPa}$ and $1 \%$ respectively. For Sikadur 330 (Figure $3 \mathrm{~b}$ ) the tensile strength was $28 \mathrm{MPa}$, the Young modulus $3745 \mathrm{MPa}$ and tensile strain to break was $0.9 \%$, while the values reported by datasheets were $30 \mathrm{MPa}, 4500 \mathrm{MPa}$ and $0.9 \%$, respectively. Thus, the obtained mechanical properties are in good agreement with the reported datasheets values indicating that the prepared samples exhibited excellent quality.

The most typical obtained failure mode of CFRP was XGM (explosive gage middle) failure mode defined by CFRP standard. The failure mode started by a SGM (longitudinal splitting gage middle) failure mode but finally cracks propagation led to a XGM failure mode. For epoxies 


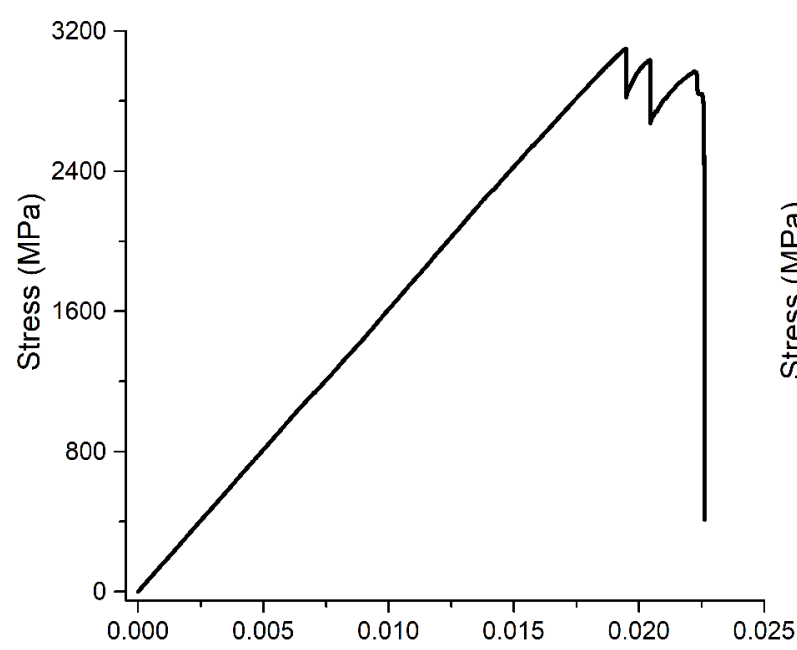

(a)

Strain $(\mathrm{mm} / \mathrm{mm})$

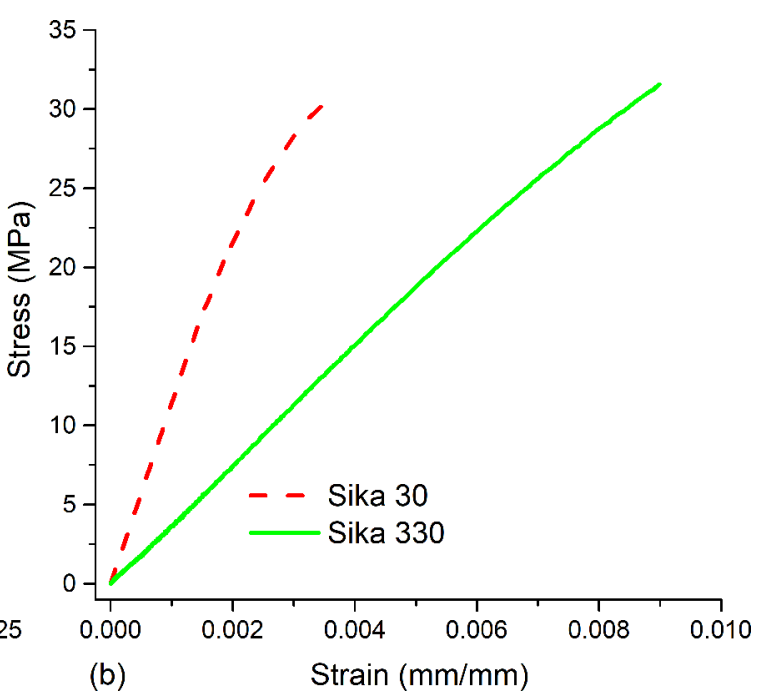

Figure 3. (a) Sikacarbodur Stress-Strain curves. (b) Sikadur 30 and Sikadur 330 stress-strain curves relationship.

Table 2. Tensile Strength, Young Modulus and Tensile strain to break results for all studied materials.

\begin{tabular}{cccc}
\hline & $\begin{array}{c}\text { Sikacarbodur } \\
\text { S512 }\end{array}$ & Sikadur 30 & $\begin{array}{c}\text { Sikadur } \\
330\end{array}$ \\
\hline $\begin{array}{c}\text { Tensile Strength } \\
(\mathrm{MPa})\end{array}$ & 3,051 & 30 & 28 \\
$\begin{array}{c}\text { E-modulus(MPa) } \\
\text { Tensile strain to } \\
\text { break (\%) }\end{array}$ & 166,738 & 12,049 & 3,745 \\
$\begin{array}{c}\text { Absorbed energy } \\
\left(\mathrm{MJ} / \mathrm{m}^{3}\right)\end{array}$ & 35.86 & 0.4 & 0.9 \\
\hline
\end{tabular}

samples were considered only those samples were failure occurred in the gage length.

Considering the amount of absorbed energy (toughness) as the area under the stress-strain curve, it was obtained as the mathematical integration of stress-strain curves shown in Figure 3. The plots of Figure 3 depicted that all materials have a brittle behavior, and the results presented in Table 2 indicate that sikacarbodur S512 presents higher capacity to absorb energy $\left(35 \mathrm{MJ} / \mathrm{m}^{3}\right)$ than the epoxies adhesives (Sikadur $30=0.06 \mathrm{MJ} / \mathrm{m}^{3}$ and Sikadur 330 $=0.13 \mathrm{MJ} / \mathrm{m}^{3}$ ). However, sikadur 330 has better mechanical behavior than sikadur 30 due to its higher value of strain to break, meaning better capacity to absorb energy by deformations under similar tensile strength (Figure $3 b$ ). The difference in the capacity of absorbing energy between the adhesives indicates that under the same tensile strength sikadur 330 will be deformed much more than sikadur 30 , which is a desired behavior in structural design since deformations before failure is a way to indicate structural problems in an element. The differences in absorbed energy and in the brittle behavior of the materials were further investigated by SEM.

\subsection{Scanning Electron Microscopy (SEM) analysis}

\subsubsection{Sikacarbodur S512 cross section surface before tensile test}

Figure 4a presents a typical SEM micrograph of longitudinal distribution of fibers in sikacarbodur S512 sample. It is observed that fiber diameter remains constant all over the length of the plate and that the resin layer due to manufacturing process presents changes in thickness. In the cross-section of image Figure $4 \mathrm{~b}$, it is observed that fibers are close packaged, and the resin is covering the fibers, although some localized cracks and bubbles can be observed. This effect may be attributed either to the processing of material or the SEM sample preparation. However, fiber discontinuities (shown by arrows) and fiber misalignments (shown by line $\mathrm{AB}$ ) observed at Figure 4a could not be provoked by the SEM sample preparation. Besides, Figure $4 \mathrm{~b}$ indicates the presence of both, some carbon fiber and interfacial cracks (shown by arrows), whereas Figure $4 \mathrm{c}$ is showing a cross section without cracks in carbon fibers, meaning that both fiber discontinuities and fiber misalignments are mostly produced by the CFRP plate manufacturing.

Figure $4 \mathrm{~d}$ shows a cross-section SEM image of Sikacarbodur S512 material where the volume fraction of carbon fiber and resin were calculated. To determinate the carbon fiber volume fraction, first it was calculated the carbon fiber diameter using Image J software by measuring the diameter of 200 carbon fibers, and the obtained average diameter was $6.7 \mu \mathrm{m}$. Then the volume fraction of resin and carbon fiber was calculated as shown in Table 3 , and results present a carbon fiber volume fraction of $63 \%$ and $37 \%$ 

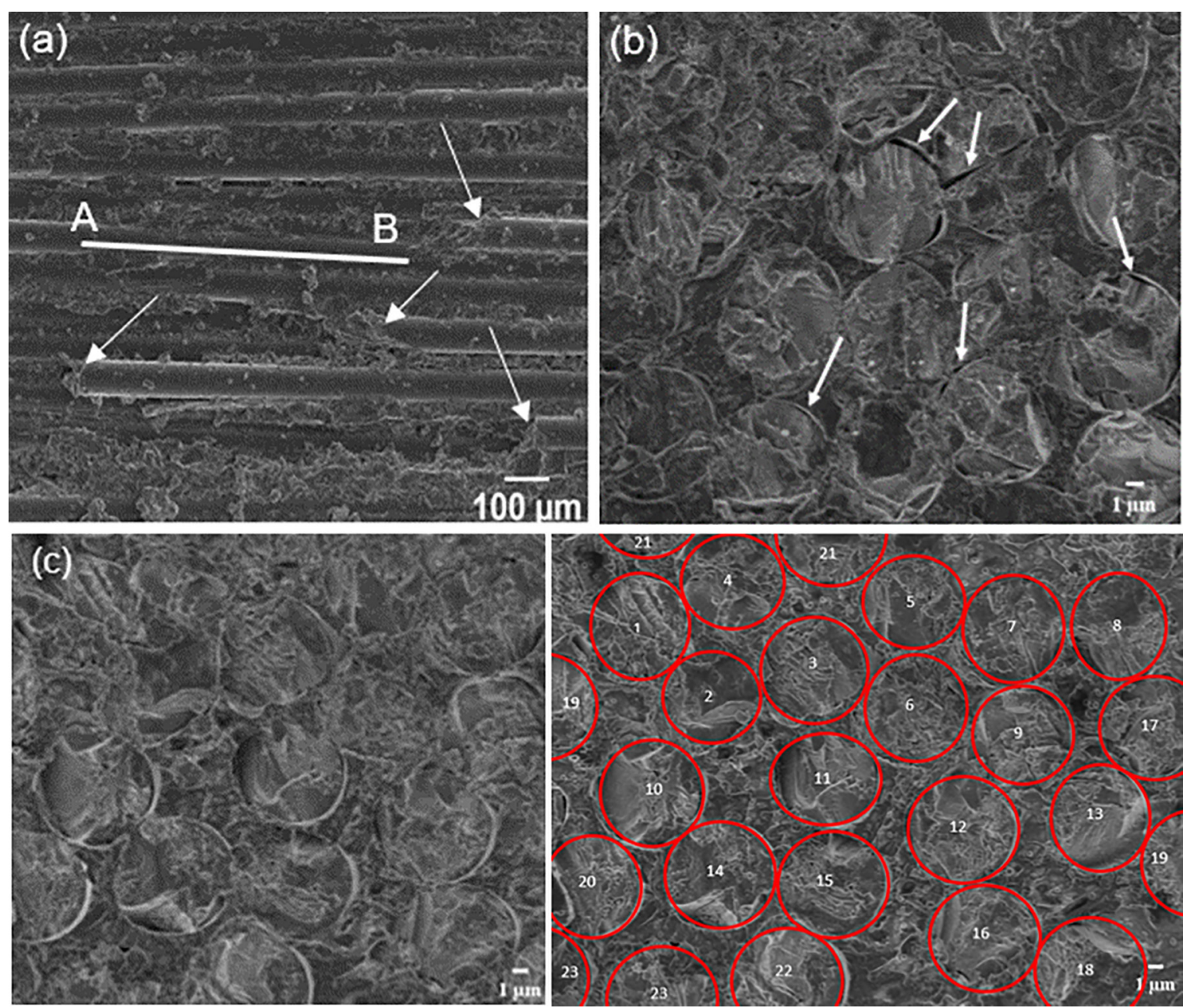

Figure 4. (a) SEM image of longitudinal direction of Sikacarbodur S512 material. (b) SEM cross-section image of Sikacarbodur S512 material. (c) SEM cross-section image of Sikacarbodur S512 material before tensile tests. (d) Typical SEM image of carbon fiber volume fraction.

Table 3. Carbon fiber volume fraction of Sikacarbodur S512 material.

\begin{tabular}{lcc}
\hline Composite area & 1266.5 & $(\mu \mathrm{m})^{\wedge} 2$ \\
\hline Fiber diameter & 6.7 & $\mu \mathrm{m}$ \\
Total of fibers & 23 & units \\
Total area of fibers & 802 & $(\mu \mathrm{m})^{\wedge} 2$ \\
Fiber volume fraction & 63.3 & $\%$ \\
Resin volume fraction & 36.7 & $\%$ \\
\hline
\end{tabular}

resin volume fraction. This means that Sikacarbodur S512 has enough carbon fiber volume to ensure the maximum mechanical properties at the lowest cost.

\subsubsection{Carbon fiber standard tensile test failures surfaces}

Figure 5a-b illustrate SEM images of Sikacarbodur S512 before and after tensile tests, and the observed failure is typically of a brittle material where failure occurs suddenly.
Figure 5c shows that fiber failure surface is non-planar and irregular with serrated aspect; no necking shape was observed. Moreover, Figure 6 exhibits a small amount of matrix debris (cohesive fracture) surrounding some carbon fibers. Indeed, adhesive fracture observed in Figure 6 was the predominated failure mode, even though this is not the desire failure mode. It is also important to notice that no shrinkage in diameter of fiber was observed after tests, assuring a brittle fracture of fibers. Figure 6 describes the sequence of failure of carbon fiber starting by the interfacial crack propagation. The interfacial cracks can avoid the force to be transferred in a properly way, generating a matrix debonding, which finally pull out carbon fibers (right side in Figure 3a). Moreover, fiber-matrix interface failure (adhesive fracture) due to tensile stress concentration in fiber-matrix interface is observed, and Horst ${ }^{14}$ observed a similar behavior for glass fibers. Matrix among fibers are restricted to be deformed by the adhesion between matrix and fibers and once fibers started to be deformed, the local stress in matrix increased 


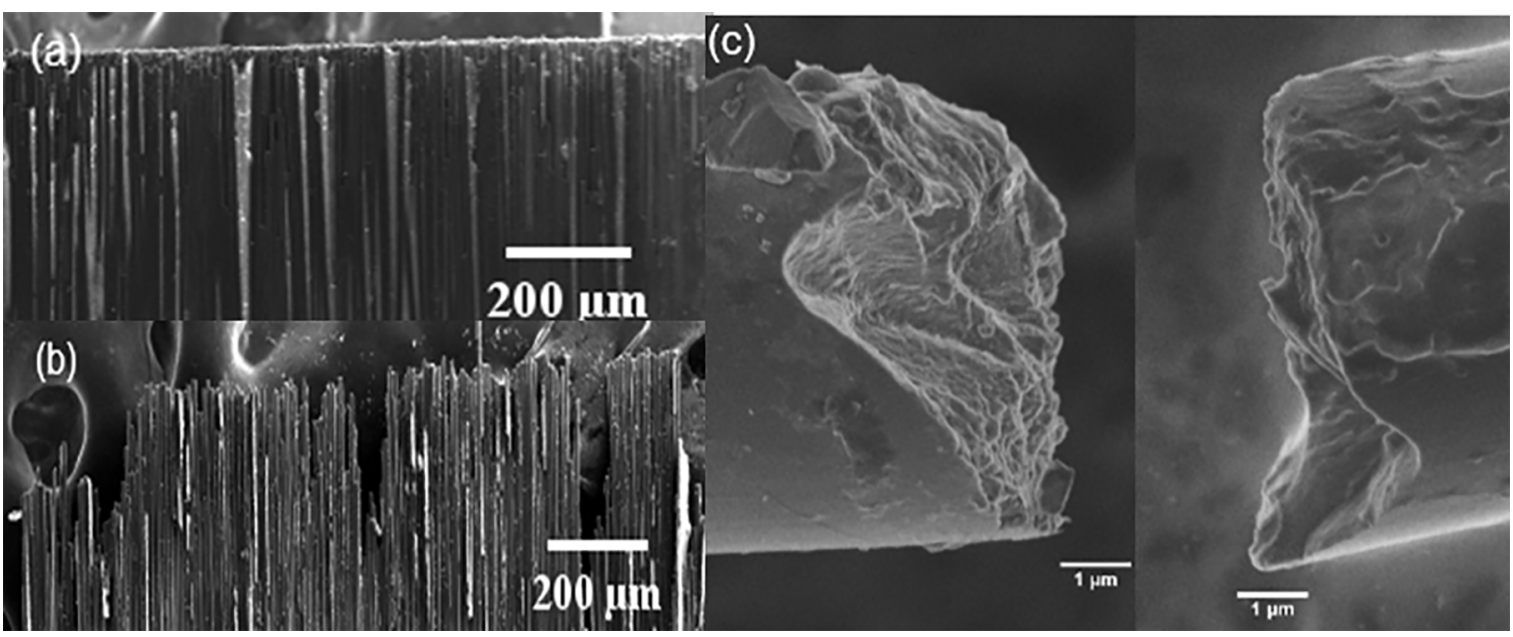

Figure 5. SEM image of Sikacarbodur S512 (a) before the tensile test and (b) after tensile test. (c) SEM image of carbon fiber failure surfaces.
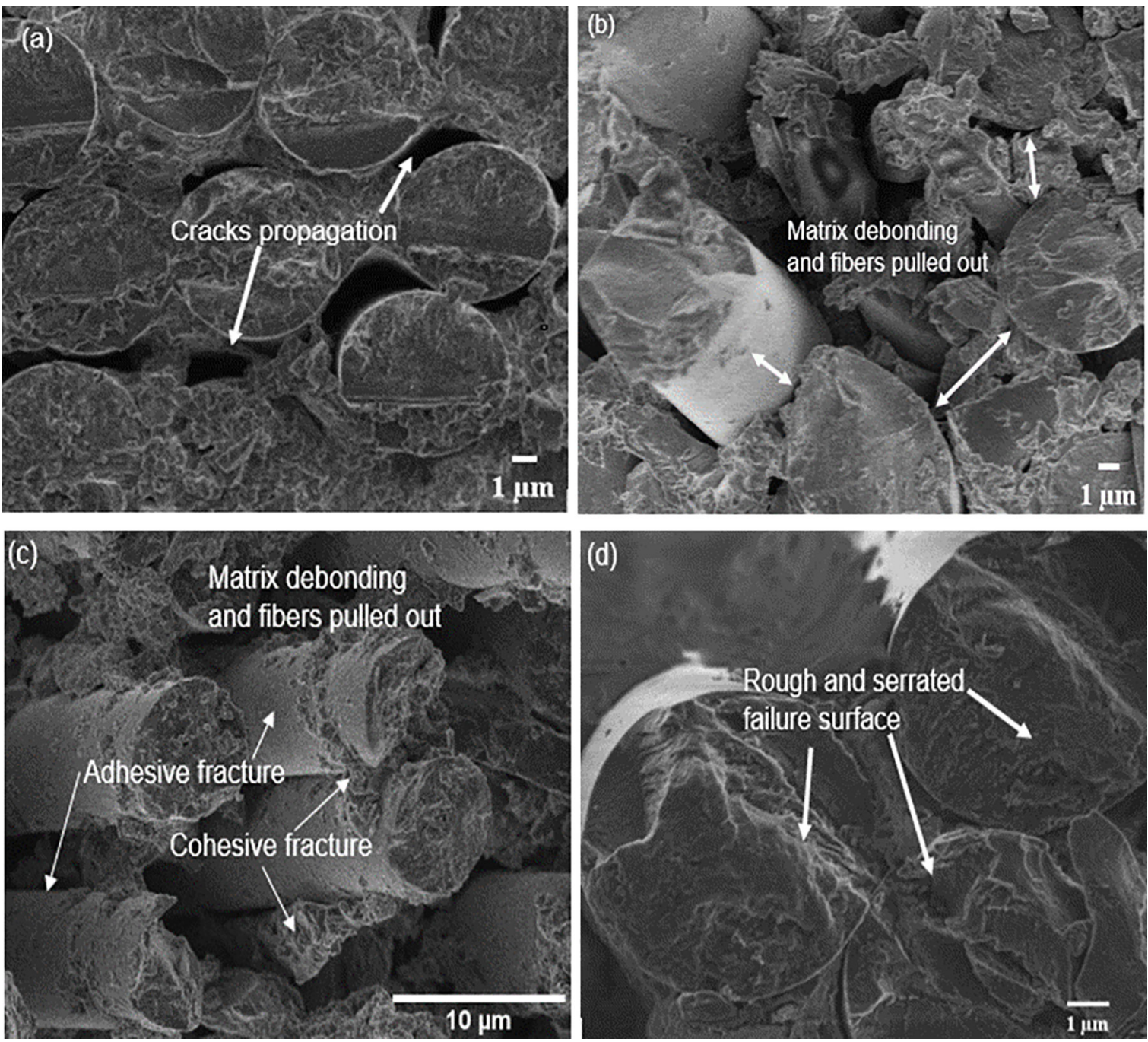

Figure 6. SEM image of carbon fiber failure sequence. 
and interfacial cracks (adhesive fracture) are observed. Regarding the failure observed, Sikacarbodur S512 plate is not a ductile material, as observed in Figure 3a, and the matrix cannot transfer properly the force among fibers due to cracks propagations and tensile stress concentrations in fiber-matrix interface. Figure 6 shows that the failure direction is perpendicular to fiber and load direction; i.e., some carbon fiber failures are consequence of fiber manufacturing defects (as shown in Figure 4) such as misalignments, discontinuities and cracks on fiber surface.

To enhance the adhesion between fibers and epoxy resin Mohammed ${ }^{20}$ used sizing agent of carbon nanotube (CNT) in carbon fiber or in neat epoxy resin. Hongwei ${ }^{21}$ concluded that using novalac resin in the fiber sizing was the most effective way to increase the bonding between the carbon fiber and the epoxy resin. Nevertheless Massimiliano ${ }^{23}$, Hassein $^{8}, \mathrm{Kim}^{1}$, among other researchers observed that when fastening CFRP to a steel element the failure occurs at the adhesive-steel interface. The failure mode when strengthen a concrete beam could be shear failure, flexural failure and FRP debonding, as observed $\mathrm{Aram}^{7}$ and Mohammed ${ }^{22}$. Therefore, when using FRP as retrofitting materials the failure occurs in the interface zone or a cohesive fracture mode defined by concrete failure whereas the FRP remains without damage, indicating that to enhance the adhesion between fiber and epoxy resin in a composite material depends on the desired application.

\subsubsection{Sikadur 30 micrograph analysis}

Figure 7a shows a backscattered electron (BSE) image of sikadur 30 cross section before the tensile test. It is possible to identify two different phases: a predominated granular phase (region 1 and Figure 7b) having more backscattered electrons, which produce brighter regions; and a predominated continuous phase (region 2 and Figure 7c) that reflect less electrons, appearing darker in the image. In addition, the interfacial phase (located in the interception zone between
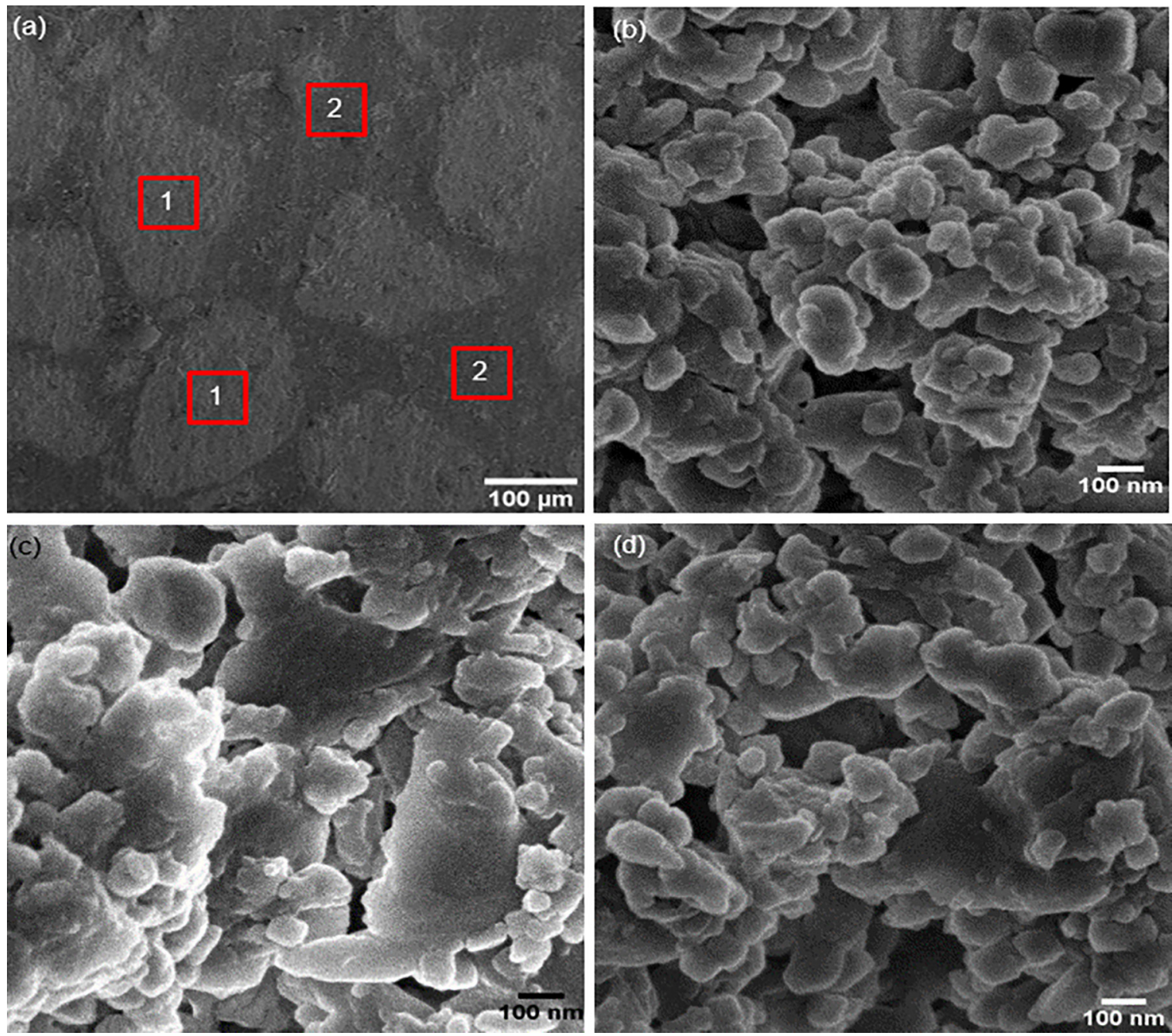

Figure 7. a) SEM image of Sikadur 30 cross-section surface before tensile test. (b) Predominated granular phase, magnified image of region 1 (c) Predominated continuous phase, magnified image of region 2 (d) Interfacial phase between region 1 and region 2. 
granular phase and continuous phase) is also observed. The material seems to be dense although some micro-sized bubbles are observed. However, observing the high resolution images of sikadur 30 illustrated in Figures $7 b-d$, it is found that material presents a porous surface, which should be related to the brittle failure. Force transferring is affected by porosity and the material is not able to develop a necking behavior by diffusing its cross section. Some air bubbles were observed in the cross section, as result of samples preparing procedure and these ones could be avoided if a vacuum environment system is settled during the preparing procedure. However, regarding that during the application of the material in a retrofitting project is not common the used of any vacuum system, those defects were considered as a normal consequence of the procedure followed to prepare the samples, and mechanical properties must be determined considering them.

Figure 8a presents a rough, irregular and nonplanar surface of sikadur 30 material after the tensile test. Material presents many granular particles over the continuous phase of the resin inside the concave surface. Figure $8 \mathrm{~b}$ is a high magnification image of region 1 and it shows that concave surfaces are composed by a continuous phase of the resin coated by fine granular particles. Figure $8 \mathrm{c}$ shows in detail the mixing between fine granular particles and continuous phase of the resin found in region 2, while there is a part of the cross section in the cast where is composed just by the continuous phase of the resin, as shown in Figure $8 \mathrm{~d}$ (zoom of region 3).

Before tensile test, there was a part in the cast cross section governed by fine granular particles (Figure 7) but after tensile tests, the surface became rough and irregular, and the granular particles were mixed with a continuous phase of the resin. Regarding the continuous phase, it remains constant but some cracks are observed as consequence of strength concentration.

Crosslinking of the adhesive itself is one of the factor used to measure the adhesive efficiency. Figure 3 shows the
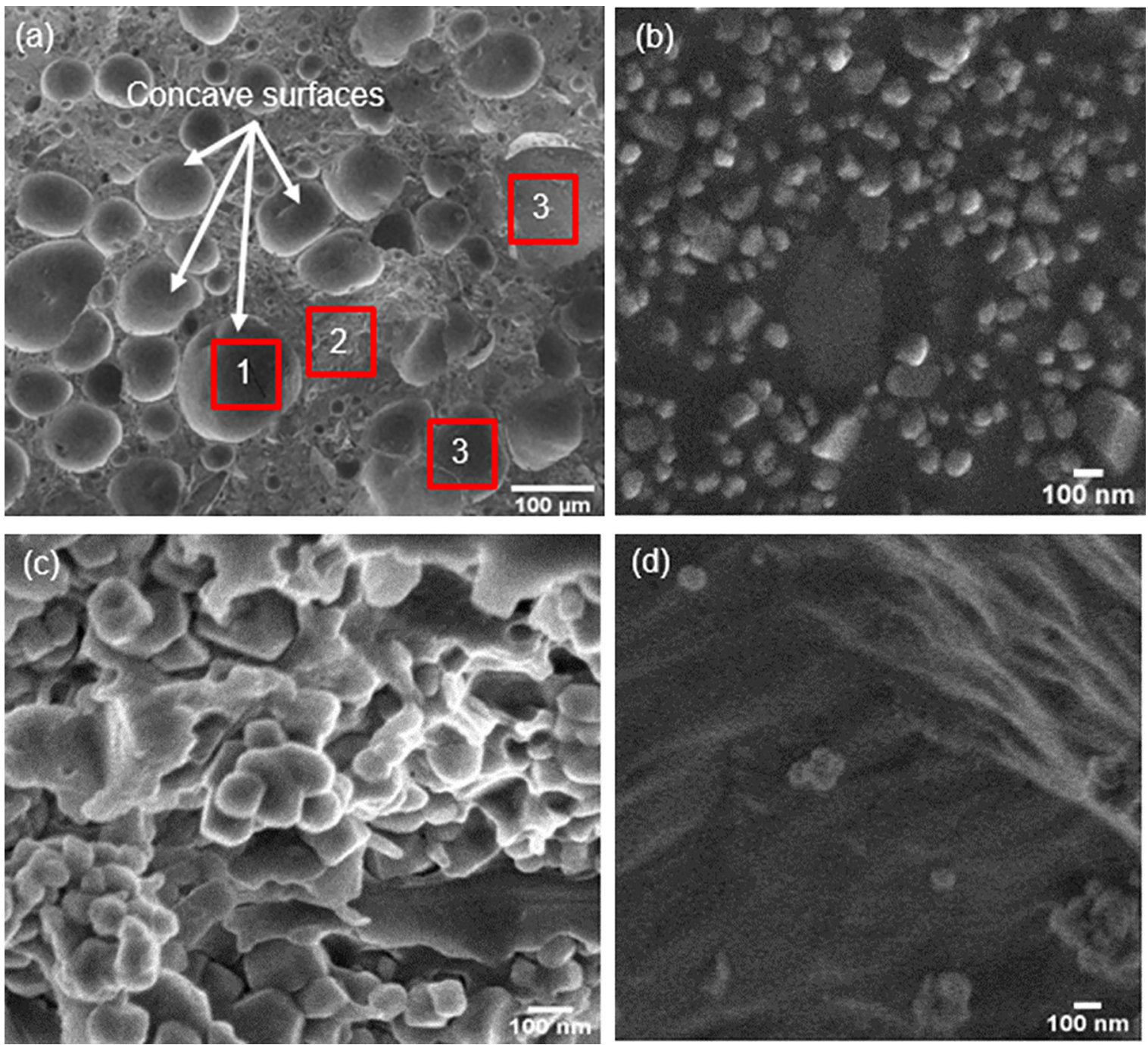

Figure 8. SEM image of Sikadur 30 sample after tensile test. Figures 8b,c and d are magnified images of regions 1, 2 and 3, respectively. 
crosslinking performance in term of stress-strain behavior of the material until covalent bonds are broken. Here the crosslinking performance is described as follow; the failure procedure started in region 3, where some groove are shown without fine granular particles indicating that bonds between fine granular particles and the continuous phase were broken therefore fine granular particle were expelled. Simultaneously failure was occurring in region 1 , where is observed the continuous phase coated by fine granular particles, but the particles are not so concentrated as before the tensile test, indicating that some bonds were also broken. Finally, region 2 was less affected than the adjacent regions, although some cracks are observed indicating that it was reached by the subjected stress. This failure procedure indicates that covalent bonds inside continuous phase could be improved to break in a slowly way by taking larger deformations before breaking up.

\subsubsection{Sikadur 330 micrograph analysis}

Figure 9a shows a typical surface SEM image of sikadur 330, showing a homogenous distribution of the granular and the continuous phases. This low magnification image does not present cracks or bubbles, and material appears good density. However, the high resolution image of sikadur 330 surface exhibited in Figure 9b shows a porous surface constituted by fine particles and a continuous phase. The presence of particles leads the material to have a brittle behavior avoiding the diffusing of its cross section during tensile test.

Figure 10a presents a typical sikadur 330 surface after the tensile test. The surface presents some micro cracks (red arrows) propagation in the continuous phase surrounding the granular phase which is outspread all over the curve inwards of the concave surface. Figure 10b (zoom from region 1) shows the fine granular phase of the resin scattered all over the continuous phase in the inward of the concave surface. It is important to mention that particles are not as concentrated as they were before the tensile test. However, as shown in Figure 10c (region 2) some parts in the cross section remained with a homogenous distribution of particles similar the observed before the tensile test, which means that the applied force distribution was not able to affect some parts of the cross section. Figure 10d shows the interfacial zone between region1 and region2, where is observed the inwards concave surface of region 1 created by tensile test. From the SEM results it is clear that sikadur 330 has less concave surfaces than sikadur 30, meaning that sikadur 330 develops more deformations before its covalent bonds start to break (Table 2 and Figure $3 \mathrm{~b}$ ), which is in agreement with the higher tensile strain to break observed for this material.

Sikadur 330 crosslinking performance is indicating that in region 1 bonds inside the continuous phase were broken because fine granular particles are observed, and cracks outside region 1 indicates the zones of stress concentration. Region 2 was not affected as region 1 nevertheless; region 2 addressed the stress distribution to the most critical zone. In this material, it was not observed any region presenting the continuous phase without any granular particles (as observed in Figure 8d for sikadur 30). Thus, the results indicate that bonds inside continuous phase of sikadur 330 are stronger than bonds of sikadur 30. Consequently, sikadur 330 has bigger strain to break than sikadur 30 and a bigger capacity to absorb energy, although they have similar tensile strength (Table 2 and Figure 3b).

The results obtained from the detailed study of morphological characteristics of sikacarbodur S512, sikadur 30 and sikadur
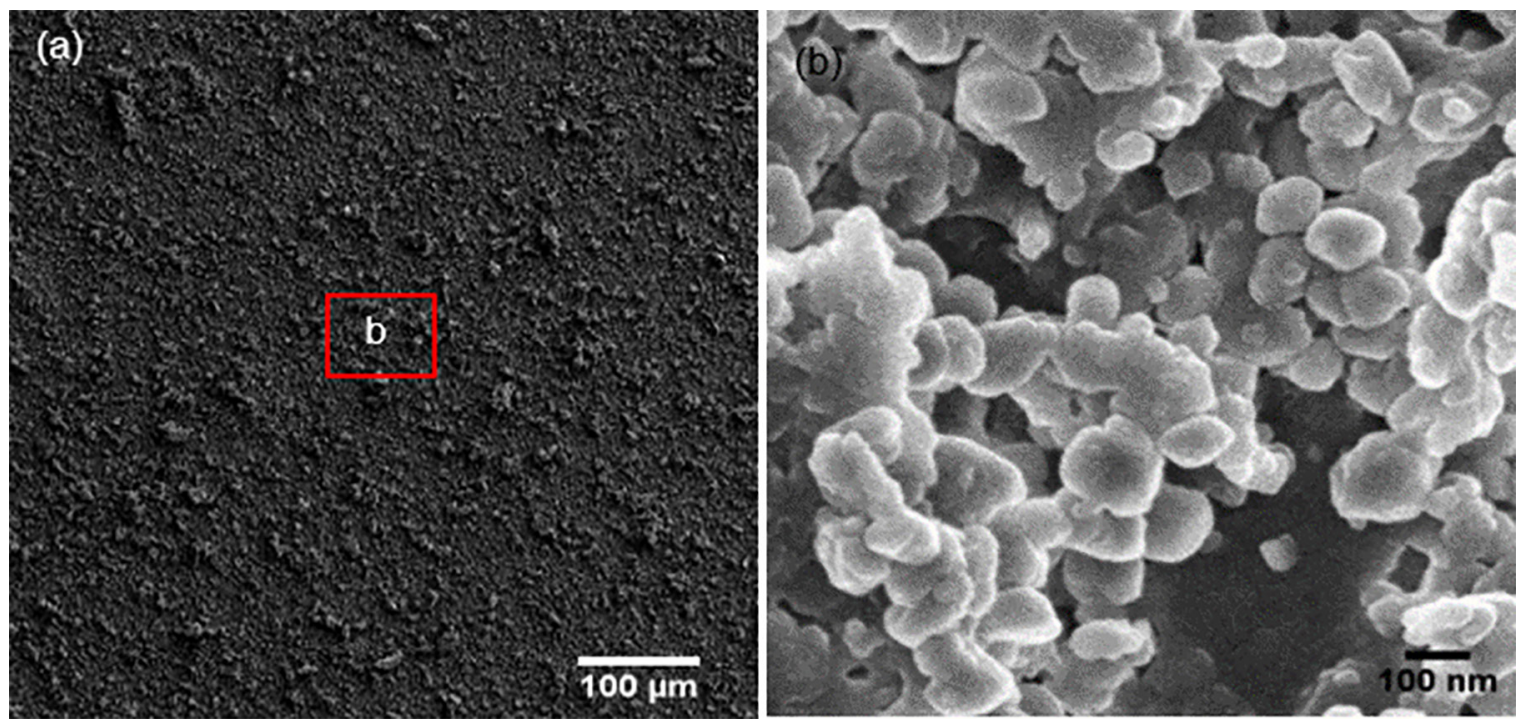

Figure 9. a) Low magnification and b) high resolution typical SEM image of Sikadur 330 cross-section surface before the tensile test. 

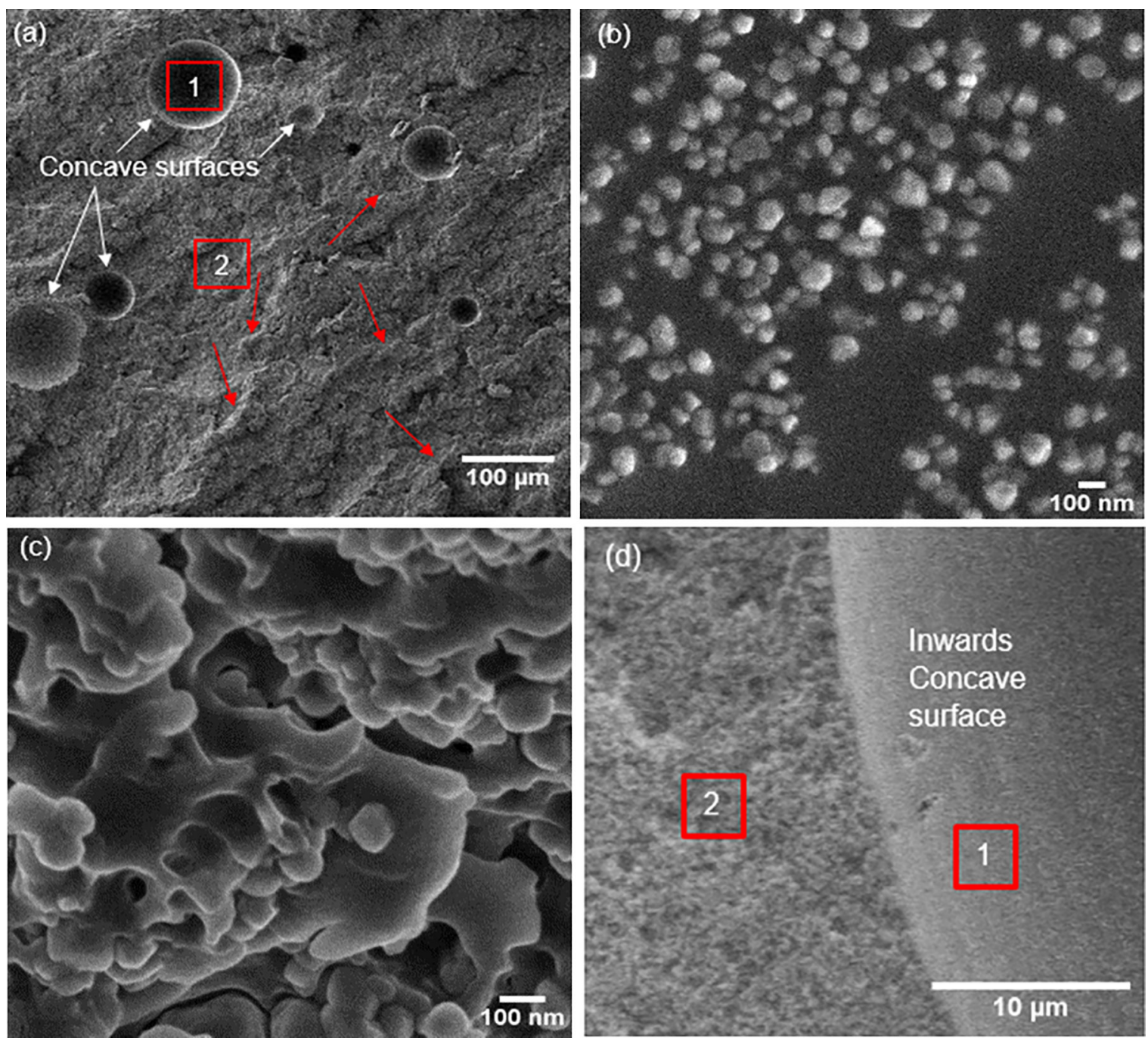

Figure 10. SEM image of Sikadur 330 cross-section surface after tensile test. Figure $10 \mathrm{~b}$ ) and c) are magnified images of regions 1 and 2 , respectively. Figure $d$ is the interface between region 1 and region 2.

330 materials by scanning electron microscopy enabled us to understand in deep way the critical aspects of applying composites and resins in practical. Besides, it was possible to correlate the morphology of material with some mechanical properties, showing that the higher amount of concave surfaces on sikadur 30 after tensile test in comparison to sikadur 330 material is related to the higher tensile strain to break exhibited by the sikadur 330 resin. Besides, it shows the importance of using advanced techniques of characterization, like SEM, to understand better the mechanical properties. Certainly, similar approach can be used for other materials in civil engineering.

\section{Conclusions}

Sikacarbodur S512 micrograph analysis shows fracture behavior is addressed by the interface zone (contact zone between fiber and resin) which is affected by tensile stress concentration and cracks propagations. Fiber-matrix interface failure mode due to tensile stress concentration in fiber-matrix interface occurs after covalent bonds are broken, affecting the load transferring to carbon fibers. Thus, matrix debonding occurs and finally carbon fibers are pulled out, which is related to the brittle behavior of Sikacarbodur S512 plate, once matrix cannot properly transfer the force among fibers.

Micrograph analysis before and after tensile test of Sikadur 30 and Sikadur 330 shows that they have a continuous phase and a granular phase. In both resins covalent alloys are broken, however sikadur 30 showed the most critical behavior because its fine granular particles are expelled out whereas sikadur 330 remained its fine particles linked to its continuous phase after tensile test. This indicates that sikadur 330 has better mechanical behavior under uniaxial tensile test than sikadur 30, and this better behavior can be observed when their tensile strain to break and absorbed energy capacity are compared. 


\section{Acknowledgments}

Acknowledgments are addressed to COIMBRA groups and CNPq Brazilian funding agency for financial support (proc \#447760/2014-9 and \#443138/2016-8). We also need to acknowledge Sika Company for providing the raw materials. Mechanical tests were provided by the engineering department of UNESP-Bauru. We would like to thank LMA-IQ for the use of SEM facilities.

\section{References}

1. Kim YJ, Harries KA. Fatigue behavior of damaged steel beams repaired with CFRP strips. Engineering Structures. 2011;33(5):1491-1502.

2. Täljsten B, Hansen CS, Schmidt JW. Strengthening of old metallic structures in fatigue with prestressed and non-prestressed CFRP laminates. Construction and Building Materials. 2009;23(4):1665-1677.

3. Mertz DR, Gillespie JW Jr. Rehabilitation of steel bridge girders through the application of advanced composite materials. Washington: Transportation Research Board / National Research Council; 1996; 35 p.

4. Ghafoori E, Motavalli M, Botsis J, Herwig A, Galli M. Fatigue strengthening of damaged metallic beams using prestressed unbonded and bonded CFRP plates. International Journal of Fatigue. 2012;44:303-315.

5. Dong JF, Wang QY, Cuan ZW. Structural behaviour of RC beams externally strengthened with FRP sheets under fatigue and monotonic loading. Engineering Structures. 2012;41:24-33.

6. Amir A, Shahawy M. Behavior of concrete columns confined by fiber composites. Journal of Structural Engineering. 1997;123(5):583-590.

7. Aram MR, Czaderski C, Motavalli M. Debonding failure modes of flexural FRP-strengthened RC beams. Composites Part B: Engineering. 2008;39(5):826-841.

8. Hassein Abed G. Effects of temperature on the adhesive bonding in steel beams reinforced with CFRP composites. [Thesis]. Southampton: University of Southampton, Faculty of Engineering and the Environment; 2012. 208 p.

9. Michels J, Widmann R, Czaderski C, Allahvirdizadeh R, Motavalli M. Glass transition evaluation of commercialy available epoxy resins used for civil engineering applications. Composites Part B: Engineering. 2015;77:484-493.

10. Mcnutt JN. Damage repair of bridge superstructures using bonded composite patching. [Thesis]. Nashville: Faculty of the graduate school of Vanderbilt University; 2011. 373 p.

11. Gilchrist MD, Svensson N. A fractographic analysis of delamination within multidirectional carbon/epoxy laminates. Composites Science and Technology. 1995;55(2):195-207.
12. Bradley ML, Grant TS. The effect of the moisture absorbtion on the interfacial strength of polymeric matrix composites. Journal of Materials Science. 1995;30(21):5537-5542.

13. Jumahat A, Soutis C, Jones FR, Hodzic A. Fracture mechanisms and failure analysis of carbon fibre/toughened epoxy composites subjected to compressive loading. Composite Structures. 2010;92(2):295-305

14. Horst JJ, Spoormaker JL. Fatigue fracture mechanisms and fractography of short-glassfibre-reinforced polyamide 6. Journal of Materials Science. 1997;32(14):3641-3651.

15. Arif MF, Saintier N, Meraghni F, Fitoussi J, Chemisky Y, Robert G. Multiscale fatigue damage characterization in short glass fiber reinforced polyamide-66. Composites Part B: Engineering. 2014;61:55-65.

16. Arash A, Maen A, Chad SK, Chiang FP. Effect of long-term exposure to marine environments on the flexural properties of carbon fiber vinylester composites. Composite Structures. 2015;126:72-77.

17. Liu C, Du D, Li H, Hu Y, Xu Y, Tian J, et al. Interlaminar failure behavior of GLARE laminates under short-beam three-point-bending load. Composites Part B: Engineering. 2016;97:361-367.

18. Albedah A, Khan SMA, Benyahia F, Bouiadjra BB. Effect of load amplitude change on the fatigue life of cracked Al plate repaired with composite patch. International Journal of Fatigue. 2016;88:1-9.

19. Horst JJ, Spoormaker JL. Mechanisms of Fatigue in short-glass fibre-reinforced polyamide 6. Polymer engineering and science. 1996;36;2718-2726.

20. Irshidat MR, Al-Saleh MH, Al-Shoubaki M. Using carbon nanotubes to improve strengthening efficiency of carbon fiber/ epoxy composites confined RC columns. Composite Structures. 2015;134:523-532.

21. He H, Li K, Gao F. Improvement of the bonding between carbon fibers and an epoxy matrix using a simple sizing process with a novolac resin. Construction and Building Materials. 2016;116:87-92.

22. Irshidat MR, Al-Saleh MH. Effect of using carbon nanotube modified epoxy on bond-slip behavior between concrete and FRP sheets. Construction and Building Materials. 2016;105:511-518.

23. Bocciarelli M, Colombi P, Fava G, Poggi C. Interaction of interface delamination and plasticity in tensile steel members reinforced by CFRP plates. International Journal of Fracture. 2007;146(1):79-92.

24. Korayem HA, Liu YM, Zhao XL, Duan WH. Bond Characterization of Steel-CFRP with Carbon Nanotube Modified Epoxy Adhesive via Pull-off Tests. International Journal of Structural Stability and Dynamics. 2015;15(8):1540027. 